\title{
Green Computing
}

\author{
K. Shalini, K. Naga Prasanthi \\ Department of Computer Science and Engineering, NRI Institute of Technology, \\ Agiripalli (M), Krishna District, India \\ e-mail: shalini.hi2007@gmail.com,prasanthi_komma@yahoo.co.uk
}

\begin{abstract}
Green computing is all about using computers in a smarter and eco-friendly way. It is the environmentally responsible use of computers and related resources which includes the implementation of energy-efficient central processing units, servers andperipherals as well as reduced resource consumption and proper disposal of electronic waste. Computers certainly make up a large part of many people lives and traditionally are extremely damaging to the environment. Manufacturers of computer and its parts have been espousing the green cause to help protect environment from computers and electronic waste in any way. Research continues into key areas such as making the use of computers as energyefficient as Possible, and designing algorithms and systems for efficiency-related computer technologies.
\end{abstract}

Keywords: Green computing, Resource Consumption, E- waste, Green IT

\section{Introduction}

In recent years, the "Green Information Technology" has been implemented with incredible success among companies on both local and international scale. The environmental protection aspect has become the adequate core that many industries are trying to follow in order to be more environmentally responsible [1]. Computers and electronic machines from all companies are consuming significant amounts of electricity, releasing carbon dioxide (CO2), which contributes to greenhouse gas emissions. The electrical usage is the main cause of climate change [1].Furthermore, the unwanted Information Technology (IT) hardware's also posed to environmental problems during both of production and disposal process. The name for these unwanted hardware equipments is electronic waste (E-Waste) [2]. Most companies are trying to minimize or eliminate the environmental impact of IT and to support the managing sustainable environment. In particular, Green IT is about improving or maintaining computing performance, while reducing the energy consumption and the carbon footprint [3]. However, implementing Green IT principles into practice involves the usage of many resources. The companies have to spend big amounts of money in order to reconstruct their IT infrastructure.

Green Computing or Green IT refers to environmentally sustainable computing or IT. In the article Harnessing Green IT: Principles and Practices, San Murugesan defines the field of green computing as "the study and practice of designing, manufacturing, using, and disposing of computers, servers, and associated subsystems such as monitors, printers, storage devices, and networking and communications systems efficiently and effectively with minimal or no impact on the environment". Green IT also strives to achieve economic viability and improved system performance and use, while abiding by our social and ethical responsibilities. Thus, green IT includes the dimensions of environmental sustainability, the economics of energy efficiency, and the total cost of ownership, which includes the cost of disposal and recycling. [4]

This paper is structured as follows: Section 2 tells about the history of Green Computing. Section 3 and 4 depicts the need for green computing and its principles. Section 5 describes the approaches to green computing. Section 6 describes Industrial implementations of green computing. Section 7 gives details about some of the industries implementing green computing practices. Section 8 gives benefits of Green Computing. Section 9 gives several tips for green computing. Section 10 concludes the paper. 


\section{History}

The U.S Environment Protection Agency launched energy star, a voluntary labeling program in year 1992, which is designed to promote and recognize energy-efficiency in monitors, climate control equipment, and other technologies. This resulted in the widespread adoption of sleep mode in computers and electronics popular among consumer electronics. The term "green computing" was probably introduced after the Energy Star program began. The logo of the energy star is given below

Concurrently, the Swedish organization TCO Development launched the TCO certification program to promote low magnetic and electrical emissions from CRT-based COMPUTER DISPLAYS; this program was later expanded to include criteria on energy consumption, ergonomics, and the use of hazardous materials in construction. The Organization for Economic Co-operation and Development (OECD) has published a survey of over 90 government and industry initiatives on "Green ICTs", i.e. information and communication technologies, the environment and climate change. The report concludes that initiatives concentrate on greening ICTs rather than tackling global warming and environmental degradation through the use of ICT applications. In general, only $20 \%$ of initiatives have measurable targets, with government programs including them more frequently than business associations. Many governmental agencies have continued to implement standards and regulations that encourage green computing. The energy star program was revised in October 2006 to include stricter efficiency requirements for computer equipment, along with a tiered ranking system for approved products. More than 26 US States that have established state-wide recycling programs for obsolete computers and consumer electronics equipment. Green Computing Impact Organization ( $\mathrm{GClO}$ ) is a non-profit organization dedicated to assisting the end-users of computing products in being environmentally responsible motivating community of environmentally concerned IT leaders who pool their time, resources, and buying power to educate, broaden the use, and improve the efficiency of, green computing products and services.

\section{Need for green computing}

The extensive use of computers and IT has made our life easier and as such the use of IT is ever on the increase resulting in greater power consumption. Greater power consumption means greater emission of greenhouse gases like carbon dioxide. The Figure 1 depicts the energy usage in a PC.

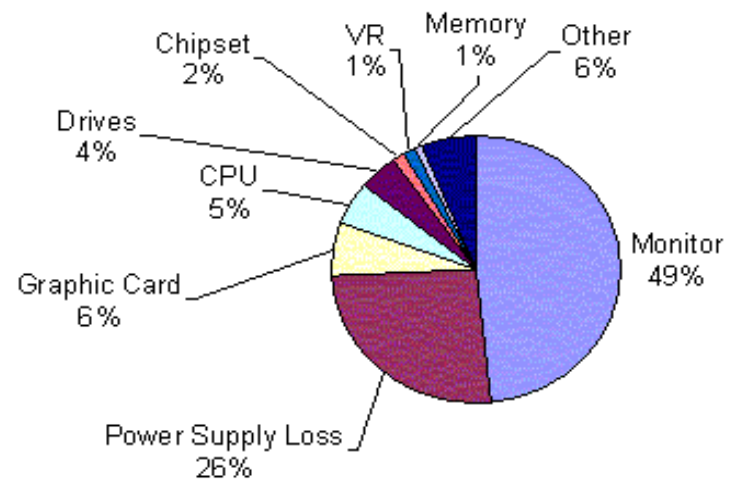

Figure 1. Energy use of PC

It is observed that most of the computer energy is often wasteful. This is because we leave the computer ON even when it is not in use. The CPU and fan consume power, screen savers consume power even when the system is not in use. Insufficient power and cooling capacities can also results in loss of energy. It is observed that most of the datacenters do not have sufficient cooling capacities. This results in environment pollution. This could be because 
of defects in Manufacturing techniques, packaging, disposal of computers and components. Another effect is because of toxicity. There are toxic chemicals used in the manufacturing of new computers as well as disposal of old computers and components which can enter the food chain and water. The toxic chemicals are [5]:

a) Lead used in soldering of printed circuit boards. Lead can cause damage to the central and peripheral nervous system, blood systems and kidneys.

b) Mercury used in batteries, switches. Mercury spreads out in water transforming into methylated mercury that can cause chronic damage.

c) Cadmium used in resistors for chips and in semiconductors. Cadmium is classified as toxic, these compounds accumulate in the human body, particularly the kidneys.

\subsection{Energy Usage Profile (EUP) for efficient power consumption}

Power save was specifically developed as not to hinder day-to-day operations, allowing IT to set strict parameters on when energy-saving actions are implemented. No unwanted power-downs and no lost productivity. Even power companies in the North America are now offering significant rebates to organizations and individuals that utilize recognized methods to reduce power consumption. The Green500 provides rankings of the most energy-efficient super-computers in the world. Green500.org shows that a prototype of IBM's next generation Blue Gene/Q supercomputer is No. 1 on the list in terms of energy efficiency. According to Green500.org, IBM supercomputers are the most energy-efficient in the world. To check the energy usage profile of a computer system we can classify our system into following areas Hardware EUP:

By catching and then restraining the power consumption of various hardware components of our system viz. Hard disks, towers and monitors. [6]

Table 1. Sample Power Usage in Watts

\begin{tabular}{cccc}
\hline Component & Idle & Average & Maximum \\
\hline CPU & 40.8 & & 130 \\
HDD & 14.35 & & 17 \\
DIMM1 & 3 & & 3 \\
DIMM2 & 3 & 3 \\
Video & 18.3 & 25.6 \\
NIC & 4.95 & & 4.95 \\
CD/DVD & 2 & & 18 \\
Other electrical & $\sim 297.35$ & & 398.45 \\
components & & & \\
Total & 383.75 & 454.39 & 600 \\
\hline
\end{tabular}

\subsection{Application's EUP}

By developing the power saver algorithms, which back-senses the idleness of our system components and cut the power of that particular wing.

Operating system EUP: By attaching the utilities to the operating systems to monitor the user or process so that the power flow can be hold enough, if not required for particular span of time.

By manufacturing all the internal as well as external components in green is also not a bad practice to aware the user of the computer system [7]. Whereas, various perceptive organizations have already been placed their steps to aware the computer users about green computing revolution such as:
1. Green web surfing
2. Green browsers
3. Green with Yahoo!
4. Green Firefox
5. Ecosearch 
While millions of people tap into Google without considering the environment, a typical search generates about 7 grams of $\mathrm{CO} 2$. Boiling a kettle generates about 15 grams. Google operates huge data centers around the world that consume a great deal of power," said Alex Wissner-Gross, a Harvard University physicist whose research on the environmental impact of computing is due out soon. "A Google search has a definite environmental impact."[6]

\subsection{Greenseng: A green search engine to conserve energy}

Greenseng is a standard search engine, pulling results from Google's Custom Search to produce results. But instead of relying on a dubious method of energy conservation, CO2Stats measures the amount of energy used by its servers and the computers of its users and purchases renewable energy certificates. By using Greenseng search engine, the carbon emissions of the electricity consumption are neutralized by CO2Stats.

If you have green site certification then you are also appended in the list of the bodies doing their efforts to implement the green computing.

\subsection{Get Green Site Certification for your website}

To get the green site certification for your web site registers your website at www.co2stats.com. The site will give answers to the following relevant questions also:

a. What is Green Certified Site?

b. How does Green Certified Site work?

c. Who uses Green Certified Site?

d. Is Green Certified Site easy to use?

e. Are reseller/enterprise solutions available?

And the benefits you get after getting the green site certifications are:

a. Improve your visitor engagement.

b. Neutralize your site's footprint.

c. Improve your site's energy efficiency.

d. Get more traffic with a green website.

e. Full international support.

\section{Green it principles}

The environmental impact towards IT, creates many issues such as growing accumulation of greenhouse gases or modifying the climate world and weather pattern [1], as Figure 2. The producing of electricity is the major cause of the climate change, because coal and oil are used to generate the electricity, releasing carbon dioxide $(\mathrm{CO} 2)$ gas during the process [1].

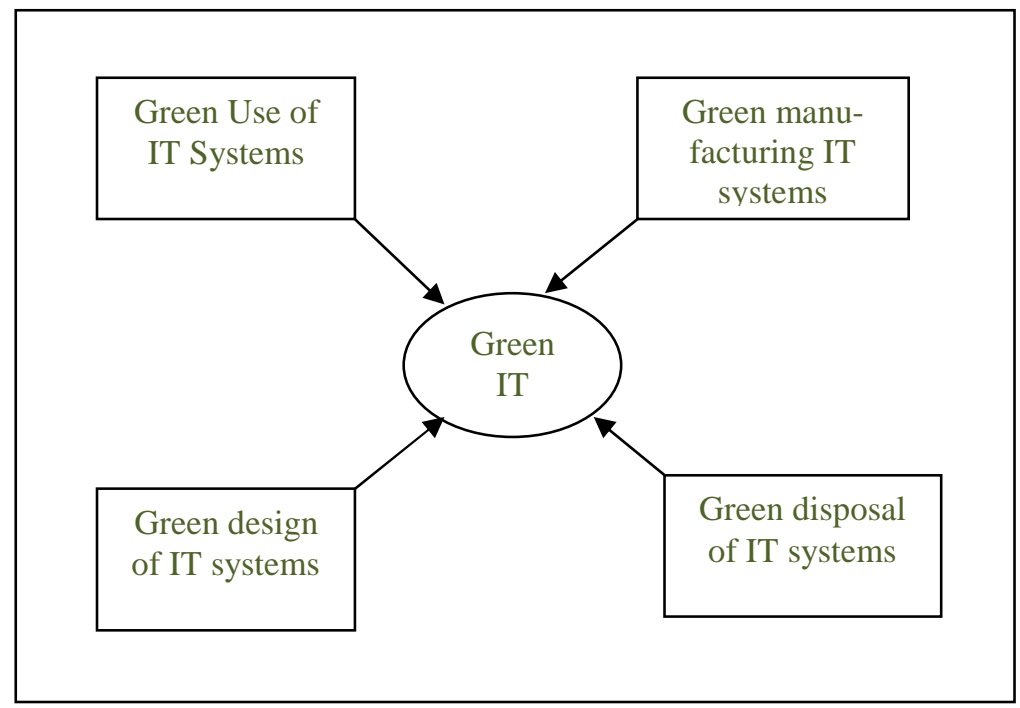

JTI Vol. 1, No. 1, March $2013: 1-13$ 
Figure 2. Green IT principles

The principles of Green IT were created not only to protect the environment and to save energy, but also to reduce the company's expenses on the long-term scenario [3]. The Green IT principles show the concepts of reducing the environmental impact. There are four key green IT principles, which are focused on different areas and activities.

1. Green use: Reduce the energy consumption of data centers, computers and other information systems and use them in the environmental ways e.g. virtualization, turning off computer when not in use, etc.

2. Green design: Design energy efficient and environmentally sound components, computers, servers and equipment's and concern more on the future of electronic parts e.g. eco-friendly design, LED monitor, etc.

3. Green manufacturing: Every process in manufacturing electronic components, computers and other associate subsystems should imply a low or no impact on the environment.

4. Green disposal: In this practice the company should plan refurbishment and reuse of old computers. Also, recycling process for unwanted computers or other electronics components should be prepared.

\section{Approaches to green computing 5.1. Virtualization}

Computer virtualization refers to the abstraction of computer resources, such as the process of running two or more logical computer systems on one set of physical hardware. The concept originated with the IBM mainframe operating systems of the 1960s, but was commercialized for x86-compatible computers only in the 1990s. With virtualization, a system administrator could combine several physical systems into virtual machines on one single, powerful system, thereby unplugging the original hardware and reducing power and cooling consumption [8]. Several commercial companies and open-source projects now offer software packages to enable a transition to virtual computing. Intel Corporation and AMD have also built proprietary virtualization enhancements to the $x 86$ instruction set into each of their CPU product lines, in order to facilitate virtualized computing. Virtualization can improve cost and energy efficiency through optimized use of existing and new computing and storage capacity, electricity, cooling, ventilation and real estate [7].

\subsection{Terminal Servers and thin clients}

Terminal servers have also been used in green computing methods. Terminal Services for Windows and the Aqua Connect Terminal Server for Mac, both deliver operating systems to end users. Using this method, users connect into a central server. All of the computing is done at the server level but the end user experiences the operating system. There has been an increase in using terminal services with thin clients to create virtual labs.

As one senior partner at a 100 -employee services firm reports, "[Thin clients have] no CPU, no RAM, no moving parts, and connect to the virtual desktop environment. Our typical computer used up to a 250-watt power supply; our thin client uses a 4.8-watt power supply, so the reduction in electricity usage is 97,98 percent, with all the functionality". Using thin clients with a terminal server delivers the Windows or Mac operating system to end users while also decreasing energy costs and consumption [9].

\subsection{Power Management}

The Advanced Configuration and Power Interface (ACPI), an open industry standard, allows an operating system to directly control the power saving aspects of its underlying hardware. This allows a system to automatically turn off components such as monitors and hard drives after set periods of inactivity. In addition, a system may hibernate, where most components (including the CPU and the system RAM) are turned off[10]. ACPI is a successor to an earlier Intel-Microsoft standard called Advanced Power Management, which allows a computer's BIOS to control power management functions.

Some programs allow the user to manually adjust the voltages supplied to the CPU, which reduces both the amount of heat produced and electricity consumed. This process is called undervolting. Some CPUs can automatically undervolt the processor depending on the workload; this technology is called "SpeedStep" on Intel processors, 
"PowerNow!"/"Cool'n'Quiet" on AMD chips, LongHaul on VIA CPUs, and LongRun with Transmeta processors.

\subsection{Power Supply}

Desktop computer power supplies (PSUs) are generally $70-75 \%$ efficient, dissipating the remaining energy as heat. An industry initiative called 80 PLUS certifies PSUs that are at least $80 \%$ efficient; typically these models are drop-in replacements for older, less efficient PSUs of the same form factor. As of July 20, 2007, all new Energy Star 4.0-certified desktop PSUs must be at least $80 \%$ efficient.

\subsection{Storage}

Smaller form factor (e.g. 2.5 inch) hard disk drives often consume less power per gigabyte than physically larger drives. Unlike hard disk drives, solid-state drives store data in flash memory or DRAM. With no moving parts, power consumption may be reduced somewhat for low capacity flash based devices. Even at modest sizes, DRAM based SSDs may use more power than hard disks, (e.g., 4GB i-RAM uses more power and space than laptop drives). Flash based drives are generally slower for writing than hard disks. As hard drive prices have fallen, storage farms have tended to increase in capacity to make more data available online. This includes archival and backup data that would formerly have been saved on tape or other offline storage. The increase in online storage has increased power consumption. Reducing the power consumed by large storage arrays, while still providing the benefits of online storage, is a subject of ongoing research.

\subsection{Video Card}

A fast GPU may be the largest power consumer in a computer. Energy efficient display options include No video card - use a shared terminal, shared thin client, or desktop sharing software if display required. Use motherboard video output - typically low 3D performance and low power. Reuse an older video card that uses little power; many do not require heat sinks or fans. Select a GPU based on average wattage or performance per watt.

\subsection{Display}

LCD monitors typically use a cold-cathode fluorescent bulb to provide light for the display. Some newer displays use an array of light-emitting diodes (LEDs) in place of the fluorescent bulb, which reduces the amount of electricity used by the display.

\subsection{Operating System Issues}

Microsoft has been heavily criticized for producing operating systems that, out of the box, are not energy efficient. Due to Microsoft's dominance of the huge desktop operating system market this omission may have resulted in more energy waste than any other initiative by other vendors. Microsoft claim to have improved this in Vista. This claim is disputed in the community. This problem has been compounded because Windows versions before Vista did not allow power management features to be configured centrally by a system administrator. This has meant that most organizations have been unable to improve this situation.

Again, Microsoft Windows Vista has improved this by adding basic central power management configuration. The basic support offered has been unpopular with system administrators who want to change policy to meet changing user requirements or schedules. Several software products have been developed to fill this gap.

\subsection{Materials Recycling}

Computer systems that have outlived their particular function can be repurposed, or donated to various charities and non-profit organizations. However, many charities have recently imposed minimum system requirements for donated equipment. Additionally, parts from outdated systems may be salvaged and recycled through certain retail outlets and municipal or private recycling centers. Recycling computing equipment can keep harmful materials such as lead, mercury, and chromium out of landfills, but often computers gathered through recycling drives are shipped to developing countries where environmental standards are less strict than in North America and Europe [11]. The Silicon Valley Toxics Coalition estimates that $80 \%$ of the post-consumer e-waste collected for recycling is shipped abroad to countries such as China,

JTI Vol. 1, No. 1, March 2013: 1 - 13 
India, and Pakistan. Computing supplies, such as printer cartridges, paper, and batteries may be recycled as well.

\subsection{Telecommuting}

Teleconferencing and telepresence technologies are often implemented in green computing initiatives. The advantages are many; increased worker satisfaction, reduction of greenhouse gas emissions related to travel, and increased profit margins as a result of lower overhead costs for office space, heat, lighting, etc. The savings are significant; the average annual energy consumption for U.S. office buildings is over 23 kilowatt hours per square foot, with heat, air conditioning and lighting accounting for $70 \%$ of all energy consumed. Other related initiatives, such as hotelling, reduce the square footage per employee as workers reserve space only when they need it. Many types of jobs -- sales, consulting, and field service integrate well with this technique. Voice over IP (VoIP) reduces the telephony wiring infrastructure by sharing the existing Ethernet copper. VolP and phone extension mobility also made hot desking and more practical.

\subsection{Product Longevity}

Gartner maintains that the PC manufacturing process accounts for $70 \%$ of the natural resources used in the life cycle of a PC. Therefore, the biggest contribution to green computing usually is to prolong the equipment's lifetime. Another report from Gartner recommends to "Look for product longevity, including upgradability and modularity." For instance, manufacturing a new PC makes a far bigger ecological footprint than manufacturing a new RAM module to upgrade an existing one, a common upgrade that saves the user having to purchase a new computer [8]

\section{Industrial implementations of green computing 6.1. Blackle}

Blackle is a search-engine site powered by Google Search. Blackle came into being based on the concept that when a computer screen is white, presenting an empty word page or the Google home page, your computer consumes $74 \mathrm{~W}$. When the screen is black it consumes only 59W. Based on this theory if everyone switched from Google to Blackle, mother earth would save $750 \mathrm{MW}$ each year. This was a really good implementation of Green Computing. The principle behind Blackle is based on the fact that the display of different colors consumes different amounts of energy on computer monitors [1].

\subsection{Fit-PC: a tiny PC that draws only $5 w$}

Fit-PC as Figure 3 is the size of a paperback and absolutely silent, yet fit enough to run Windows XP or Linux. fit-PC is designed to fit where a standard PC is too bulky, noisy and power hungry. If you ever wished for a PC to be compact, quiet and green-then fit- PC is the perfect fit for you. Fit-PC draws only 5 Watts, consuming in a day less power than a traditional PC consumes in 1 hour. You can leave fit-PC to work 24/7 without making a dent in your electric bill [1].

\subsection{Zonbu Computer}

The Zonbu as Figure 4 is a new, very energy efficient PC. The Zonbu consumes just one third of the power of a typical light bulb. The device runs the Linux operating system using a 1.2 gigahertz processor and $512 \mathrm{MB}$ of RAM. It also contains no moving parts, and does even contain a fan. You can get one for as little as US\$99, but it does require you to sign up for a two-year subscription" [1].

\subsection{Sunray thin client}

Sun Microsystems is reporting increased customer interest in its Sun Ray, a thin desktop client (Figure 5), as electricity prices climb, according to Subodh Bapat, vice president and chief engineer in the Eco Responsibility office at Sun. Thin clients like the Sun Ray consume far less electricity than conventional desktops, he said. A Sun Ray on a desktop consumes 4 to 8 watts of power, because most of the heavy computation is performed by a server. Sun says Sunrays are particularly well suited for cost-sensitive environments such as 
call centers, education, healthcare, service providers, and finance. PCs have more powerful processors as well as hard drives, something thin clients don't have. Thus, traditional PCs invariably consume a substantially larger amount of power. In the United States, desktops need to consume 50 watts or less in idle mode to qualify for new stringent Energy Star certification [1].

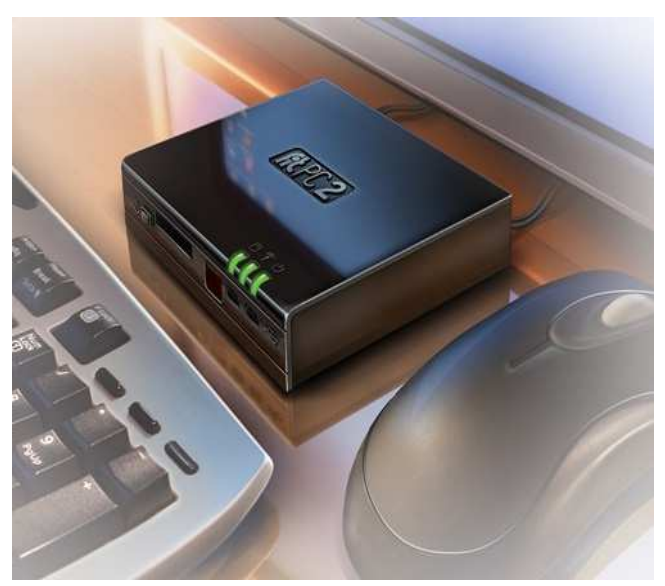

Figure 3. Fit-PC

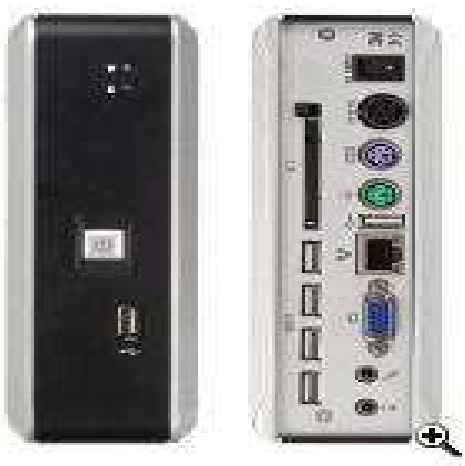

Figure 4. Zonbu computer

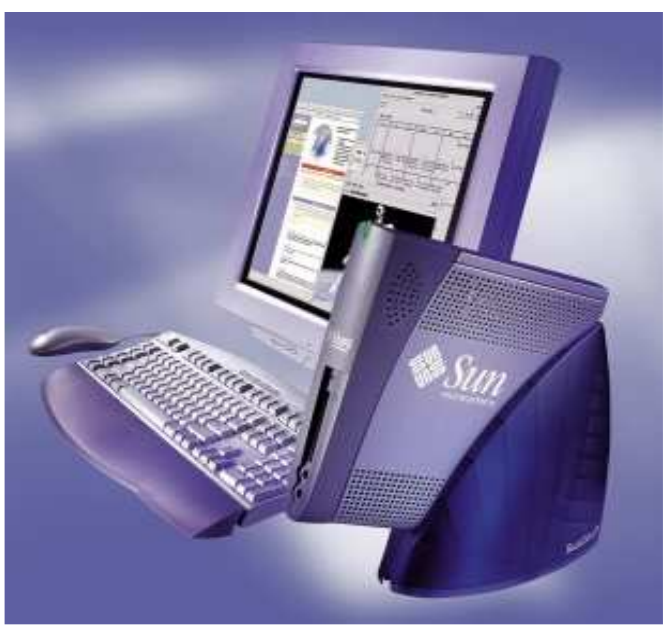

Figure 5. Sunray Thin Client 


\subsection{The Asus Eee PC and other ultra portables}

The "ultra-portable" class of personal computers is characterized by a small size, fairly low power CPU, compact screen, low cost and innovations such as using flash memory for storage rather than hard drives with spinning platters. These factors combine to enable them to run more efficiently and use less power than a standard form factor laptop. The Asus Eee PC is one example of an ultraportable. It is the size of a paperback, weighs less than a kilogram, has built-in Wi-Fi and uses flash memory instead of a hard drive. It runs Linux too.[1]

\subsection{Other implementations a. Notebooks}

Usually, notebooks are more modest than desktop PCs when it comes to the energy requirements. On average, notebook batteries last for less than two hours, so energy saving is an important issue for those who are away from a plug point for long durations. If you want to achieve maximum battery runtime then it's essential for a notebook to have energy-efficient components. The warmer the external power supply unit, the higher the electricity consumption. Apple's MacBooks or Acer-models have intelligent charging electronics that ensure the currentflow sinks below 0.1 Watts after the battery is charged. Values less than 3.0 Watts, in Samsung's Q10, for instance, are acceptable. This is known as 'conservation charging.'

\section{b. Printers and multifunctional devices}

Usually, monochromatic laser printers require less electricity than color lasers. And this is true even in the standby mode. Color lasers use more energy when they go into the standby mode instead of the sleep mode. All color lasers require more than 10 Watts when they are in standby. To conserve energy, check the settings in the printer driver [7].

\section{c. Communications and network:}

W-LAN routers, DSL modems and DECT telephones do not have a standby mode since they must always be ready for operation. But low power consumption is a must since these devices are on 24 hours a day, seven days a week.

\section{d. External hard disks}

Users are increasingly buying 3.5 inch external hard disks as backup devices for desktop and notebook computers. These are also being used to extend the system storage. Once connected, it's easy to forget that its power supply continues to draw power, even when nothing is being read or written to the disk. Only a few models have sophisticated power-saving mechanisms; Seagate devices are quite commendable. Most devices do not have a 'Power' button. The 3.5-inch hard drives need 12 Volts and therefore they have an external power supply unit (power brick). But 2.5-inch drives require just 5 Volts and they can draw power from the PC via a USB cable. Since they draw power from the PC's power supply unit, the 2.5 -inch drives will switch off automatically when the PC shuts down. Drive manufacturers are now incorporating features such as the reduced RPM low-power idle mode [7].

\section{e. DVD and video}

Older DVD players and recorders are power hogs. Some devices consume up to 25 Watts in the standby mode and a switch-off button is absent. You can save energy in most such devices with a simple trick: The HF amplifier in DVD recorders is responsible for consuming a good amount of electricity in the standby mode. The amplifier refreshes the incoming antenna signal for the television, which is perhaps connected with an antenna cable. If one places the recorder and the television next to each other and connects them to the antenna using a Tconnector, this amplification is rendered useless. Many devices have the option of completely deactivating the HF output in the set-up. Older video recorders often have sliding switches for this. 


\section{Companies following green computing}

a. Dell

Computer equipment has historically been one of the most difficult and costly products to safely dispose of. Fortunately, one of the major leaders in that field has stepped forward to make the task less daunting. Through its "no computer should go to waste" recycling program, Dell allows customers to return any Dell-branded product back to the company-for free. The company has even gone so far as to establish programs that accept computers, monitors, or printers from other companies for safe disposal, as well.

\section{b. Bank of America}

Bank of America is proving that eco-friendly operations can coexist with business growth. According to their corporate website, the company reduced paper use by $32 \%$ from 2000-2005, despite a 24\% growth in their customer base! Bank of America also runs an internal recycling program that recycles 30,000 tons of paper each year, good for saving roughly 200,000 trees for each year of the program's operation. As if that weren't enough, the company also offers employees a $\$ 3,000$ cash back reward for buying hybrid vehicles.

\section{c. HP}

The company has gotten out in front of the computer disposal issue by owning and operating enormous "e-waste" recycling plants that shred discarded, obsolete computer products into raw materials that can be recycled into the industrial food chain. HP has also agreed to take back computer equipment of all brands, and taken steps to ensure that its own products are $100 \%$ recyclable in the manner discussed above. Furthermore, the company has promised to lower its energy consumption a full $20 \%$ by the year 2010 .

\section{Benefits of green computing}

1. Reduced energy usage from green computing techniques translates into lower carbon dioxide emissions, stemming from a reduction in the fossil fuel used in power plants and transportation.

2. Conserving resources means less energy is required to produce, use and dispose of products

3. Saving energy and resources save money

4. Green computing includes changing government policy to encourage recycling and lowering energy use by individuals and business

5. Reduce the risk existing in laptops such as chemical known to cause cancer, nerve damage and immune reactions in humans.

\section{Tips for green computing}

1. Turn off your computer at night so it runs only eight hours a day. you'll reduce your energy use by 810 kwh per year and net a 67percent annual savings.

2. Purchase flat screen monitors. They use significantly less energy and are not as hard on your eyes as CRTs.

3. Unplug the electronics if not in use.

4. Consider a smaller monitor-a 14-inch display uses 40 percent less energy than a 17-inch one.

5. Enable the standby/sleep mode and power management settings on your computer [12].

Sleep mode or stand by: - conserves energy by cutting off power to your display, hard drive, and peripherals. After a pre-set period of inactivity, your computer switches to a low power state. When you move your mouse or press any computer key, you exit sleep mode and your computer takes you back to its previous operating state. Sleep mode is an especially effective way to conserve battery power in a laptop computer.

6. Power off your monitor when you are not using it instead of using screen savers[13].

7. Kill the vampires: Anything that uses a remote continues to consume power even when it's turned off-for example, when a TV is "off," it's really partially "on" so that the picture comes on quickly when you hot the remote. This is called "vampire energy use" or "phantom energy use" [14]. 


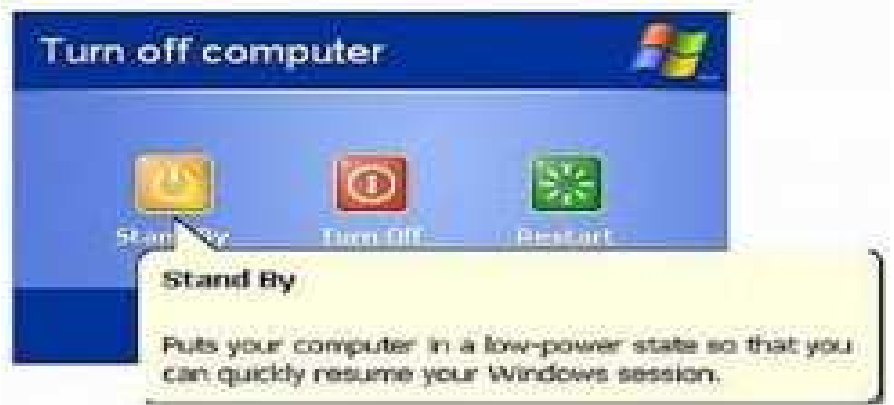

Figure 6. Stand By mode

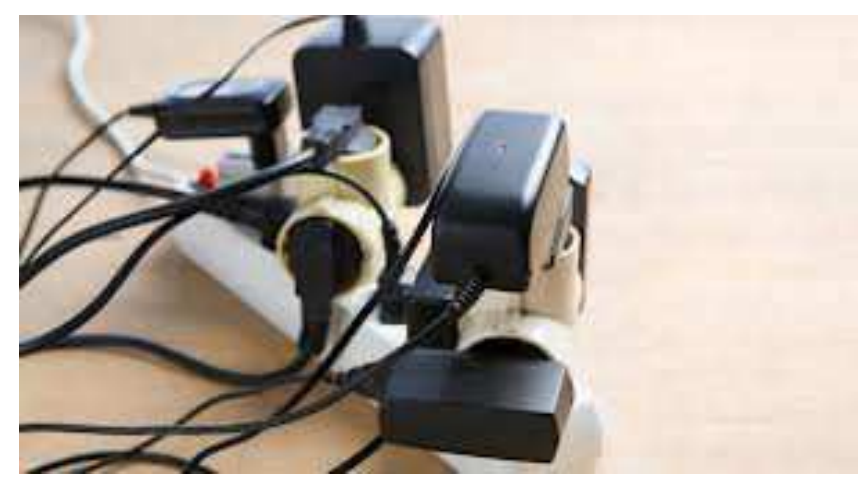

Figure 7. Phantom energy use

8. According the Department of Energy, "vampire energy loss" represents between 5 and 8 percent of a single family home's total electricity use per year. On average, that equals one month's electricity. An easy solution to it is: a surge protector with a master control outlet. Simply plug your computer into the master outlet and your peripherals into the controlled outlets. The master outlet senses your computer powers down or goes into sleep mode and automatically shuts down the controlled outlets.

9. Your peripherals no longer suck up energy when they are in standby mode.

10. Buy vegetable or non-petroleum-based inks-they are made from renewable resources require hazardous solvent.

11. Save Paper when Printing: When it comes to the environment, one of the first places most offices can improve is the giant pile of discarded paper by the network printer. Aside from obvious things you can do on your own-like printing duplex, printing to PDF, previewing before printing, and not printing hundreds of copies of an email forward to plaster around the office- there are a few other tools you can use to minimize wasting paper and ink when printing [14].

12. Recycling: Electronics Waste Can be Recycled. Recycling as Figure 8 can be defined as the process of used materials processing into new useful materials with the aim to reduce environmental pollution. The recycling process is more environmentally friendly than the process of making new stuff because it can reduce the use of new raw materials, land degradation, pollution, and energy usage and also can reduce greenhouse gases [2]. 


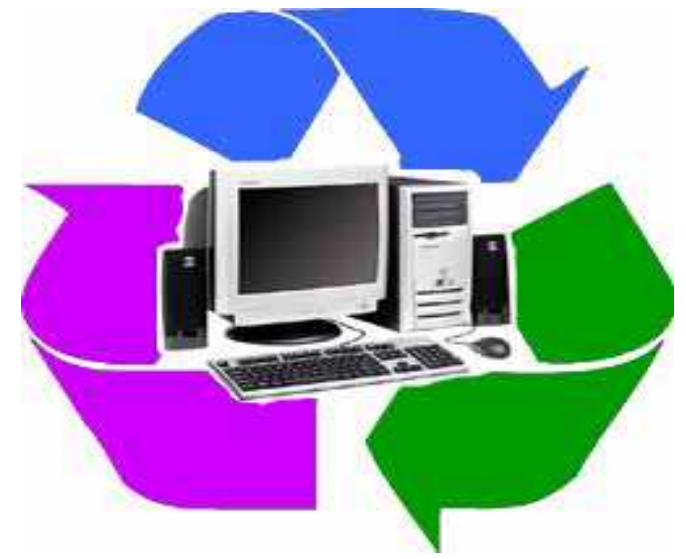

Figure 8. Recycle E-waste

\section{Case study}

Consider a medium sized educational institution; the power consumption for a PC per year can be calculated using standard EU-ENERGY CALCULATOR. The power consumption for one desktop is calculated as $124.8 \mathrm{kwh} /$ year and the cost is Rs.624 approximately (1 UNIT $=$ Rs.5).

The EU-ENERGYSTAR CALCULATOR snapshot is shown below.

\section{Energy Calculator for PC Equipment}

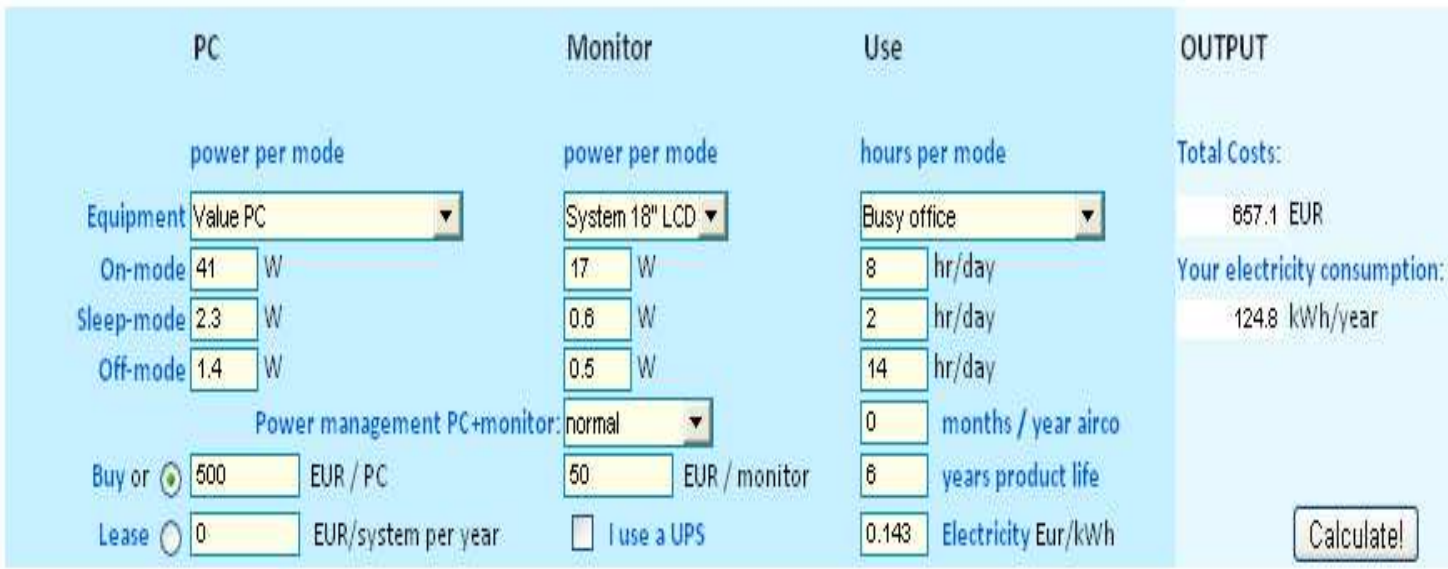

\begin{tabular}{|c|c|c|c|}
\hline Total costs split-up & EURO & Energy split-up & Wh/yea \\
\hline Equipment & 550 & On-mode & 111.3 \\
\hline Energy & 107.1 & Sleep mode & 1.3 \\
\hline Paper and toner/ink & 0 & Off-mode & 12 \\
\hline Total & 657.1 & Air-conditioning & 0 \\
\hline & & Total & 124.8 \\
\hline
\end{tabular}

Figure 9. Snapshot for energy calculator 
If we consider a computer lab with 60 systems, the cost is Rs. 38,000 approximately excluding air conditioning. If we use thin clients instead then the power consumption will be $72.6 \mathrm{kwh} /$ year and the cost for 60 systems is 22,000 . Even though the one time procurement of server and establishing server costs are there, power consumption for thin clients is much lesser thus giving more profits to the organization.

\section{Conclusion}

Adopting Green Computing Strategies make sense not only from an ethical, or moral stand-point, but from a commercial stand-point. There are many business benefits achievable through the implementation of a green computing strategy such as cost savings, resilience, disaster recovery, business continuity planning and of course public relations. Given the prolific nature of IT within today's information economy IT leaders have an excellent opportunity to significantly impact the fight against global warming, while enhancing the business operation and efficiency. So Green computing is the utmost requirement to protect environment and save energy along with operational expenses in today's increasingly competitive world.

\section{References}

[1] S Murugesan. Harnessing Green IT: Principles and Practices. IT Pro, IEEE Computer Society. 2008; 10(1): $24-33$

[2] S Ruth. Green IT - More Than a Three Percent Solution. IEEE Computer Society. 2009; 13(4): 74 78.

[3] D Wang. Meeting Green Computing Challenges. IEEE Computer Society. 2008: 1- 4.

[4] Green IT For Dummies'-Hewlett Packard Limited Edition

[5] Hazardous Technical Information Services. Bulletin. 2011; 11.

[6] Praveen Tripathi. Green computing as a mandatory revolution for proper end-of-life. Journal of Information and Operations Management. 2012; 3(1): 174- 177.

[7] "Green IT: Why Mid-Size Companies Are Investing Now".

[8] Appasami G, Suresh Joseph K. Optimization of Operating Systems towards Green Computing. International Journal of Combinatorial Optimization Problems and Informatics. 2011; 2(3): 39-51.

[9] Pradeep Shivkhare, Kumkum Sinha. A Study Of Awareness Of Green Computing Amongst The ItUsers. Pioneer Journal Of IT. 2012

[10] P Ashok Kumar and K Ravali. New Form of Green IT: Cloud Computing. VSRD-IJCSIT. 2012; 2(3): 250-255.

[11] Sk Fayaz Ahamad1, PV Ravikanth. Green Computing Future of Liveliness. International Journal of Computational Engineering Research (IJCER). ISSN: 2250-3005

[12] Prasant Singh Yadav, Vaibhav Kumar, Sunil Kumar. Green Computing-Making Technology Fruitful. International Journal Of Scientific \& Technology Research. 2012; 1(5).

[13] Mujtaba Talebi. Computer Power Consumption Benchmarking For Green Computing. Master's Thesis, Villanova University, Department of Computing Sciences. 2008.

[14] Bruce Nordman, Alan Meier and Mary Ann Piette. PC and Monitor Night Status: Power Management Enabling and Manual Turn-Off. Proceedings of the American Council for an Energy Efficient Economy (ACEEE) Summer Study on Energy Efficiency in Buildings. 2000. 